\title{
Comparative Analysis of the National Traditional Physical Education and Modern Physical Education Teaching
}

\author{
Fan Zhanjiang \\ Xinjiang Aqricultural University, Urimuqi Xinjiang, 830052
}

Keywords: national traditional sports, modern sports, modern physical education

\begin{abstract}
With the continuous development of human society, the contradictory movement between tradition and modernity is also developing. With the promotion of modern civilization, China's modern sports have come into being and have been developing continuously. Modern sports have the characteristics of fast spread and wide spread, which are not obsessed by traditional national sports. Although there are conflicts between traditional national sports and modern sports, there are also commonalities and relations between them. Modern society is deeply influenced by modern civilization and the pace of modernization is accelerating. It is the focus of modern civilization society to deal with the relationship between modernity and tradition, which affects the survival and development of human beings. Traditional national sports have two characteristics of nationality and tradition, while modern sports pay more attention to competition and appreciation, both of which have important reference significance for modern physical education teaching. Through the comparison of their relations and characteristics, the integration of national traditional sports and modern sports can be realized. Traditional ethnic sports are the epitome of politics, culture, economy and education in different periods, which can enrich modern physical education.
\end{abstract}

\section{Introduction}

China's national traditional sports include the traditional sports of the han nationality and the traditional sports of the minority nationality. These national traditional sports were originally folk traditional sports and entertainment activities, and their connotations have been enriched with the development of history. Traditional national sports include martial arts, tug-of-war, shuttlecock kicking and other sports with local ethnic colors, among which wushu is an important part of traditional national sports in China. Modern physical education teaching should explore the national traditional physical education unceasingly, integrate the national traditional physical education item in the teaching. This paper will discuss the relationship between national traditional sports and modern sports, the status quo of national traditional sports in modern sports teaching, and the fusion method between national traditional sports and modern physical education teaching.

\section{The relationship between national traditional sports and modern sports}

\subsection{The connection between national traditional sports and modern sports}

There is a mutual promotion relationship between national traditional sports and modern sports. In the age before modern civilization, national traditional sports have different characteristics in different historical periods. The development of national traditional sports is characterized by progress and stagnation, peak and low ebb interwoven. In a sense, modern sports is also the result of continuous development and improvement of national traditional sports. National traditional sports is the foundation of modern sports, and the development of modern sports has promoted the further development of national traditional sports and injected new blood into national traditional sports. Both national traditional sports and modern sports involve sports, which can achieve the goal of strengthening physical fitness. National traditional sports and modern sports promote and depend on each other. 


\subsection{National traditional sports and modern sports are different from each other}

China's national traditional sports is one of the manifestations of Chinese culture and conveys the Chinese national spirit. However, modern sports have a global character and are a worldwide form of sports. In addition, national traditional sports and modern sports have different emphases. National traditional sports have strong performance and entertainment, and emphasize the participation experience of sports players, which can show the local colors and local culture of different regions. Modern sports attach importance to competition and transcendence and take "faster, higher, stronger" as the slogan. Modern sports emphasize on inspiring human potential and pushing people beyond their limits, while also emphasizing scientific methods of physical training. The differences between traditional national sports and modern sports should be paid attention to in the modern physical education.

\section{The status quo of traditional national sports in modern physical education teaching}

\subsection{The introduction of modern physical education in traditional ethnic sports is limited}

At present, the content of modern physical education in China is still dominated by modern competitive sports, and few traditional ethnic sports are introduced. Although the physical education teaching in the school has undergone some reform, and modern physical education teaching has consciously joined some traditional ethnic sports, the form of traditional ethnic sports introduced in the school is relatively simple. According to the current situation of school physical education teaching, the physical education courses of the school are mainly ball sports, track and field sports and gymnastics sports, some schools carry out traditional ethnic sports such as martial arts. The present situation of PE teaching cannot meet the requirements of PE teaching in schools under the new curriculum reform. In the school physical education teaching, the school ignored the influence of some traditional minority sports on physical education.

\subsection{The teaching faculty of traditional ethnic physical education is weak}

Under the impetus of physical education reform, schools have consciously increased the teaching of traditional national sports programs. However, the teaching of these sports programs is difficult to carry out. At present, the traditional national sports teaching lacks experienced teachers with solid professional foundations. Physical education teachers in many schools lack the expertise of relevant national traditional sports programs and have not undergone rigorous training. The shortage of teachers' resources has put pressure on the teaching of traditional national sports. Many teachers do not understand the humanities knowledge involved in traditional national sports. Therefore, even if some schools carry out the teaching of national traditional sports, students cannot form a systematic and complete understanding of the national traditional sports in China. The teacher factor has greatly limited the integration of traditional national sports and modern sports.

\subsection{Teachers neglect human knowledge in traditional national sports}

National traditional sports are formed under the long-term accumulation of history, which combines the customs, national spirit, economic culture and geographical and humanistic characteristics of different nationalities. Influenced by the competitive nature of modern sports, some schools' physical education teachers confuse traditional national physical education with modern physical education, failing to convey the local characteristics and humanities knowledge of national traditional sports. Moreover, many physical education teachers rely on existing physical education materials and have no relevant experience. Therefore, their national traditional projects are too empty and unattractive to students. Moreover, the teaching concept of the physical education teacher's "Emphasis on surgery rather than theory" has led to the loss of humanistic color in the teaching of national traditional sports and cannot achieve the teaching purpose of inheriting national culture. 


\section{The integration of traditional national sports and modern physical education}

\subsection{Enrich the content of national traditional sports teaching}

In the process of realizing the integration of national traditional sports and modern physical education, schools need to introduce traditional national sports teaching projects in conjunction with the actual situation of the school. According to the actual geographical location of the school, teachers carry out traditional national sports teaching activities with local characteristics. The school's national traditional sports teaching should be tailored to local conditions and highlight regional characteristics. On the basis of selecting local national sports projects, the school also introduces various other sports items with ethnic regional characteristics into sports textbooks, such as Mongolian wrestling, Korean springboard, and dragon boat racing along the rivers and lakes. Diversified national traditional sports programs allow students to learn more about regional knowledge, enrich their cultural literacy, and feel the national spirit of the Chinese people.

\subsection{Both attention to competition and entertainment}

Modern sports projects carried out in modern physical education need to reflect the competitive nature. Therefore, when teaching modern sports programs, teachers should pay attention to the scientific sports training of students and let students master the basic skills of sports. In order to enhance students' understanding of sports competition, teachers can also carry out some sports competitions appropriately so that students can continue to improve in the competition. At the same time, modern physical education should pay attention to the entertainment of traditional national sports, so that students can learn happily. In order to enhance the entertainment of physical education, teachers should fully stimulate students' interest in the process of teaching national traditional sports, and create a happy and lively atmosphere for students' learning.

\subsection{Play the cultural function of physical education}

National traditional sports is a social and cultural phenomenon with strong social and cultural functions. China's national traditional sports have been influenced by Chinese traditional culture, paying attention to the individual's ideological and moral cultivation, and highlighting the functions of sports pleasure. China's national traditional sports reflect China's etiquette and wisdom, emphasizing friendly and mutual assistance in the process of sports. Integrating traditional national physical education into modern physical education can help students improve their cultural accomplishment and improve their ideological and cultural qualities. The social and cultural functions of national traditional sports can make up for the shortcomings of modern sports, and the integration of the two can complement each other. Modern physical education should pay attention to the social and cultural functions of sports and achieve quality education.

\section{Conclusion}

There are differences between traditional national sports and modern sports, and the focus of the two is different. National traditional sports have undergone a process of development and perfection, and the current national traditional sports have also incorporated some modern factors. Modern physical education should pay attention to the educational function of national traditional sports, and continuously integrate into traditional national sports teaching in practical teaching. By comparing the traditional sports of the nation with the modern sports, we can understand the relationship between the two more clearly, so as to better achieve the integration of the two.

\section{References}

[1] Mai Jia. The Development and Experience Enlightenment of National Traditional Sports in School Physical Education in China[D]. Huazhong Normal University, 2014.

[2] Zheng Chuanfeng, Li Yongkun. Analysis of the Role of National Traditional Sports in College 
Physical Education[J]. Educational modernization, 2016, 3(38):208-209.

[3] Tan Dashun. Research on the Current Situation, Prospects and Countermeasures of National Traditional Sports Activities in Colleges and Universities[J]. Journal of Southwest Guizhou National Teachers College,2016(04):67-70. 